\title{
Magnetic Fluid-Based Squeeze Film Behaviour in Curved Porous-Rotating Rough Annular Plates and Elastic Deformation Effect
}

\author{
M. E. Shimpi ${ }^{1}$ and G. M. Deheri ${ }^{2}$ \\ ${ }^{1}$ Department of Mathematics, BVM Engineering College-Vallabh Vidyanagar, Gujarat, Anand 388120, India \\ ${ }^{2}$ Department of Mathematics, Sardar Patel University, Anand, Gujarat, Vallabh Vidyanagar 388120, India
}

Correspondence should be addressed to M. E. Shimpi, mukesh.shimpi@gmail.com

Received 7 December 2011; Revised 20 June 2012; Accepted 16 July 2012

Academic Editor: Patrick De Baets

Copyright (c) 2012 M. E. Shimpi and G. M. Deheri. This is an open access article distributed under the Creative Commons Attribution License, which permits unrestricted use, distribution, and reproduction in any medium, provided the original work is properly cited.

\begin{abstract}
Efforts have been directed to study and analyze the squeeze film performance between rotating transversely rough curved porous annular plates in the presence of a magnetic fluid lubricant considering the effect of elastic deformation. A stochastic random variable with nonzero mean, variance, and skewness characterizes the random roughness of the bearing surfaces. With the aid of suitable boundary conditions, the associated stochastically averaged Reynolds' equation is solved to obtain the pressure distribution in turn, which results in the calculation of the load-carrying capacity. The graphical representations establish that the transverse roughness, in general, adversely affects the performance characteristics. However, the magnetization registers a relatively improved performance. It is found that the deformation causes reduced load-carrying capacity which gets further decreased by the porosity. This investigation tends to indicate that the adverse effect of porosity, standard deviation and deformation can be compensated to certain extent by the positive effect of the magnetic fluid lubricant in the case of negatively skewed roughness by choosing the rotational inertia and the aspect ratio, especially for suitable ratio of curvature parameters.
\end{abstract}

\section{Introduction}

It was Archibald [1] who presented the behaviour of squeeze films between various geometrical configurations for the flat surfaces. Wu [2] analyzed the performance of the squeeze film for rotating porous annular disks. Prakash and Vij [3] made use of the well-known Morgan Cameron approximation assuming the porous facing small. Murti [4] investigated the squeeze film performance in curved circular plates describing the film thickness by an exponential expression. His analysis was based on the assumption that the central film thickness was constant instead of minimum film thickness as considered by Hays [5]. Gupta and Vora [6] extended this analysis to the corresponding problem for annular plates. Patel and Deheri [7] studied the behavior of squeeze film between curved circular plates considering the film thickness described by a hyperbolic expression.
All the above studies dealt with conventional lubricants. The use of magnetic fluid as a lubricant modifying the performance of the bearing system has drawn considerable attention. Agrawal [8] investigated the performance of a porous-inclined slider bearing with a magnetic fluid lubricant. Verma [9] discussed squeeze film performance in the presence of a magnetic fluid lubricant. Bhat and Deheri [10] analyzed the squeeze film behaviour taking magnetic fluid as a lubricant between two annular disks. Here, it was found that the application of magnetic fluid lubricant enhanced the performance of the squeeze film. Of course, the magnetic fluid consisted of fine magnetic grains suspended in a magnetically passive solvent. Concerning the details of the behavior and properties of magnetic fluid, one can have a glance at Bhat [11]. However, in actual practice the flatness of the plate does not endure owing to elastic, thermal and uneven wear effects. With this point of view, Bhat and Deheri [12] analyzed the performance of magnetic 


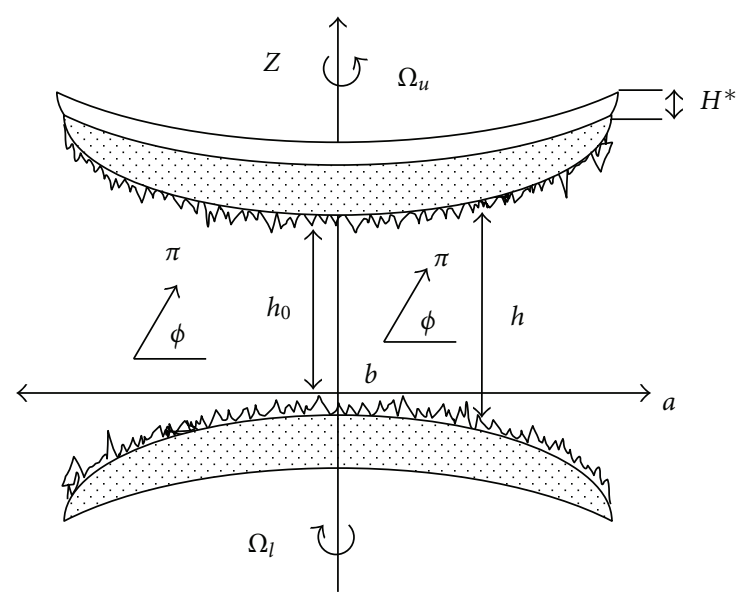

FIgURE 1: Configuration of bearing system.

fluid-based squeeze film behaviour on the configuration of Ajwaliya [13]. It was observed that the magnetic fluid lubricant significantly improved the performance of the magnetic fluid-based bearing system. Osman et al. [14] dealt with the stationary and dynamic characteristic of bearing in the presence of magnetic fluid lubricant. Tripathi et al. [15] extended the analysis of Bhat and Deheri [12] by incorporating rotation of both the plates. Lin et al. [16] considered the performance of squeeze film between curved circular plates with an electrically conducting fluid in the presence of a transverse magnetic field.

These studies underline the importance of the pressure effect of magnetic fluids and the magnetizing effect of lubricants in the lubricating process, in turn, rendering the action of both magnetic field and magnetic fluid in lubrication manifestly clear. Besides, some of these investigations suggest that, in general, the magnetic fluid can outperform nonmagnetic lubricants in evaluating the performance of squeeze film bearing system.

Recently, considerable attention has been paid to the use of magnetic fluid as a lubricant modifying the performance of bearing system. Ferrofluids/magnetic fluids are a special category of smart nanomaterials, in particular, magnetically controllable nanofluids. These types of nanofluids are colloids of magnetic nanoparticles such as $\mathrm{Fe}_{3} \mathrm{O}_{4}, \gamma$ - $\mathrm{Fe}_{3} \mathrm{O}_{4}$, $\mathrm{CoFe}_{2} \mathrm{O}_{4}, \mathrm{Co}, \mathrm{Fe}$, or Fe-C, stably dispersed in a carrier liquid. Consequently, these nanomaterials manifest simultaneously magnetic fluids and magnetic properties. These fluids find there good use in engineering and biomedical applications. In fact, in any discussion of the fluid which has magnetic properties, can be divided into the following categories it: (1) ferrofluids; (2) magnetorheological fluids; (3) dispersions of micron-sized particles, (4) fluids containing paramagnetic particles. In fact, ferrofluids/magnetic fluids are stable followed as dispersions of nanosized particles of ferro or ferromagnetic particles in a carrier liquid when a ferro-fluid is subjected to a magnetic field, magnetic field gradient, and/or gravitational field, in order that the colloidal suspension remains stable. The magnetic particles generally have to be of approximately $10 \mathrm{~nm}$ in diameter. Particles of this size, whether they are ferrite or metal, possess a single magnetic domain only; that is, the individual particles are in a permanent state of saturation magnetization. Therefore, a strong long-range magnetostatic attraction exists between individual particles. One of the most important properties of the magnetic fluids is that they can be retained at a desired location by an external magnetic field.

Liu et al. [17] analyzed the friction characteristic of different lubrication modes under alternating magnetic fluid. It was concluded that the magnetic fluid lubricant had better lubricating property than the nonmagnetic lubricant (expanded graphite) because it could cling on to friction pairs uniformly, and the endurance of magnetic fluid lubricant was better than that of nonmagnetic lubricant.

After receiving some run-in and wear, the bearing surfaces develop roughness. Even sometimes contamination of lubricants and chemical degradation of the surfaces contribute to the roughness. The roughness appears to be random in character. In order to study and analyze the effect of surface roughness on the performance of the bearing systems, several methods have been presented. Tzeng and Saibel [18] adopted a stochastic approach to mathematically model the random roughness. Christensen and Tonder [19-21] modified and developed the approach of Tzeng and Saibel [18] to propose a comprehensive general analysis for the surface roughness (both transverse as well as longitudinal) by making use of a general probability density function. Subsequently, a number of investigations made use of Christensen and Tonder's approach to investigate the effect of surface roughness (Prakash and Tiwari [22]; Prajapati [23]; Guha [24]; Gupta and Deheri [25]). Andharia et al. $[26,27]$ presented a study dealing with the effect of surface roughness on the performance of a squeeze film bearing making use of the general stochastic analysis. Hsu et al. [28] dealt with the combined effects of surface roughness and rotational inertia on squeeze film characteristics between parallel circular disks. Recently, Shimpi and Deheri [29] reported the behaviour of the performance characteristics of a magnetic fluid-based rough short bearing. Here, it was established that the combined effect of magnetization and negatively skewed roughness is significantly positive. Ting [30] considered the problem of engagement of porous clutch plates simulating it by annular plates incorporating the effect of elastic deformation and surface roughness of the porous housing. Prajapati [23] discussed the performance of a squeeze film between rotating porous circular plates and studied the effects of the surface roughness along with elastic deformation,

Prakash and Peeken [31] investigated the effect of surface roughness and elastic deformations in one-dimensional slider bearing and found the existence of strong interaction between the roughness and elastic deformation. Chatchai and Mongkol [32] described the effect of surface roughness and elastic deformation of bearing liner on the static and dynamic characteristic of journal bearings. It was proved that the roughness pattern, elastic deformation, and powerlaw index significantly affected the characteristics of journal bearing under severe operating conditions. Recently, Shimpi and Deheri [33] studied the effect of surface roughness and 


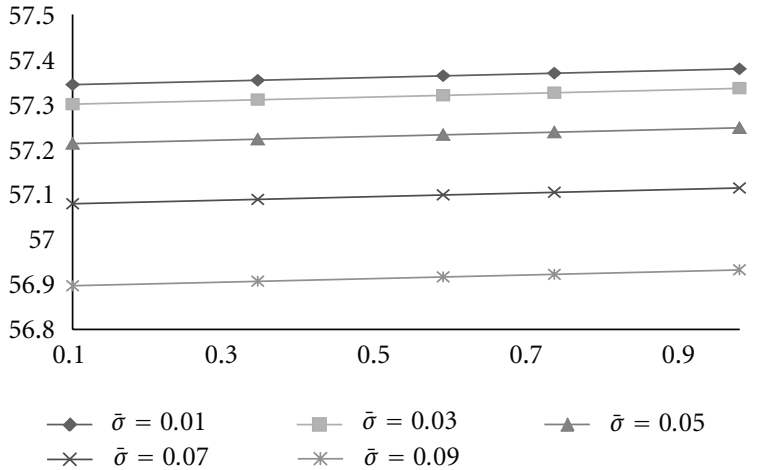

(a)

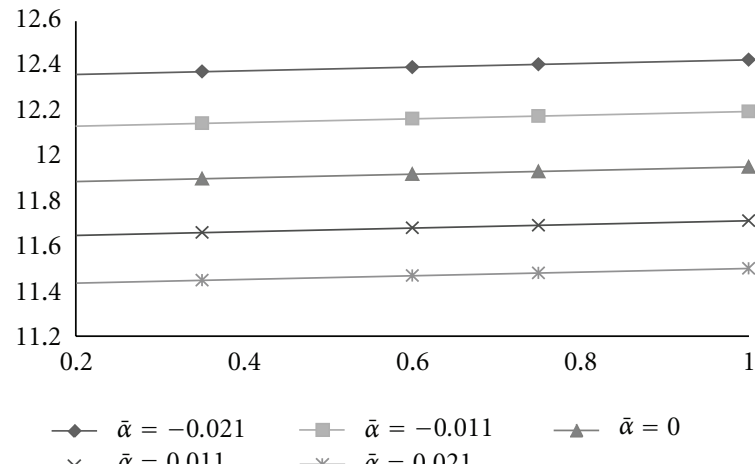

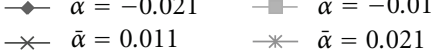

(c)

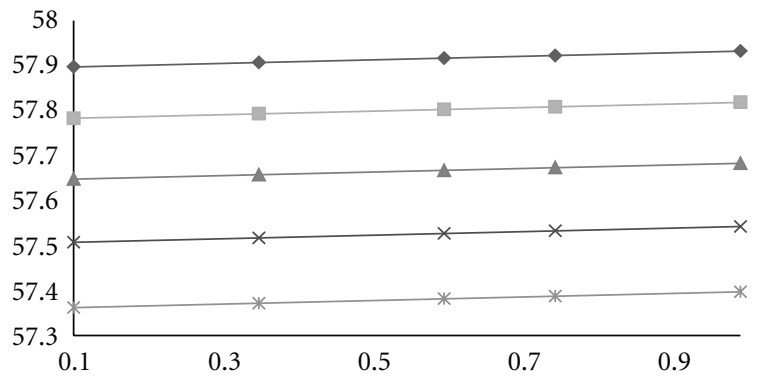

$\multimap \psi=0.0001 \rightarrow \psi=0.0008 \rightarrow \varangle \quad-\quad-\quad=0.0016$

$\star \psi=0.0024$

* $\psi=0.0032$

(e)

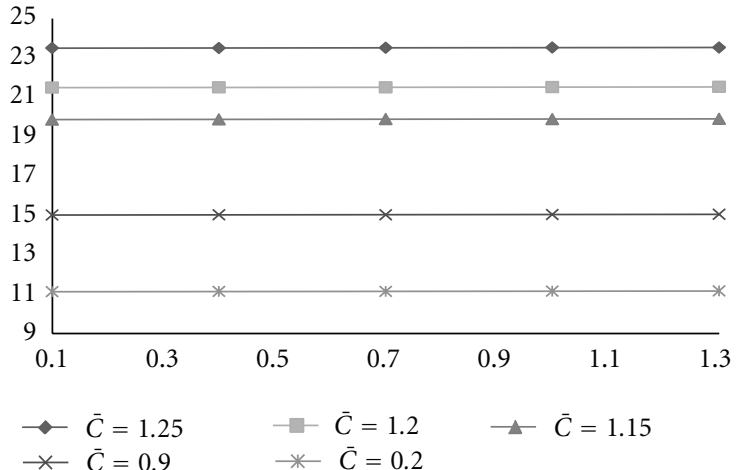

(g)

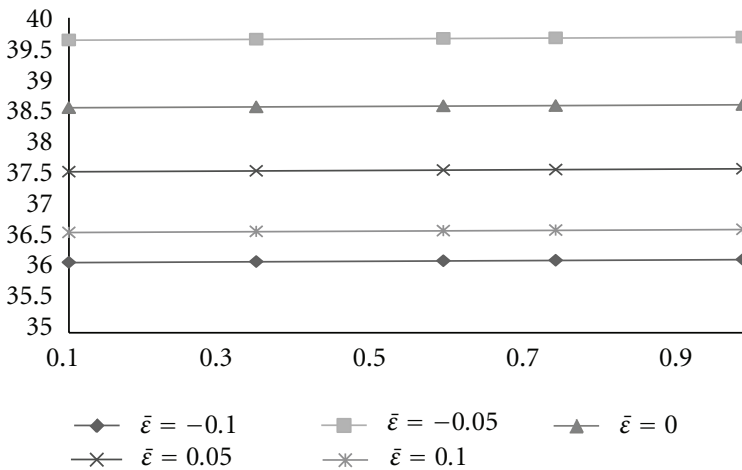

(b)

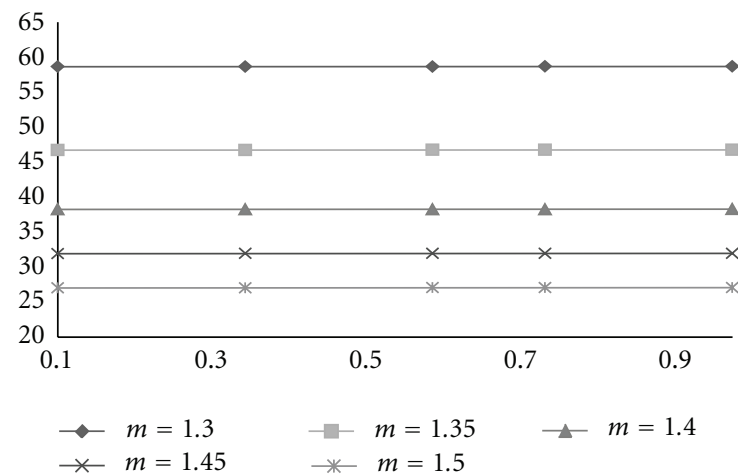

(d)

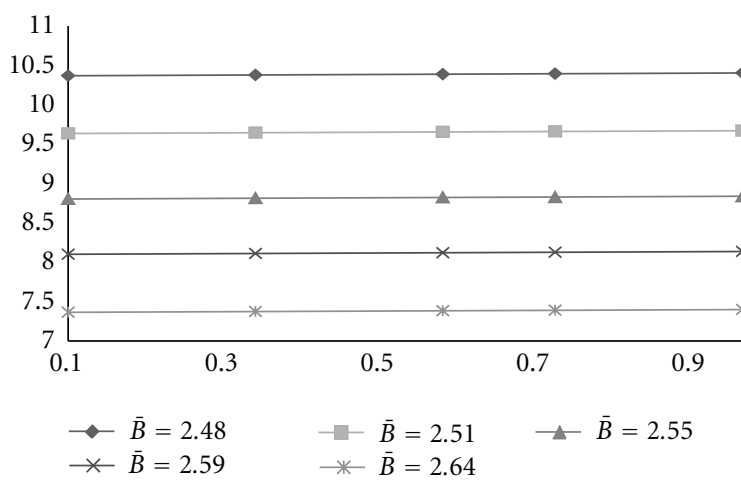

(f)

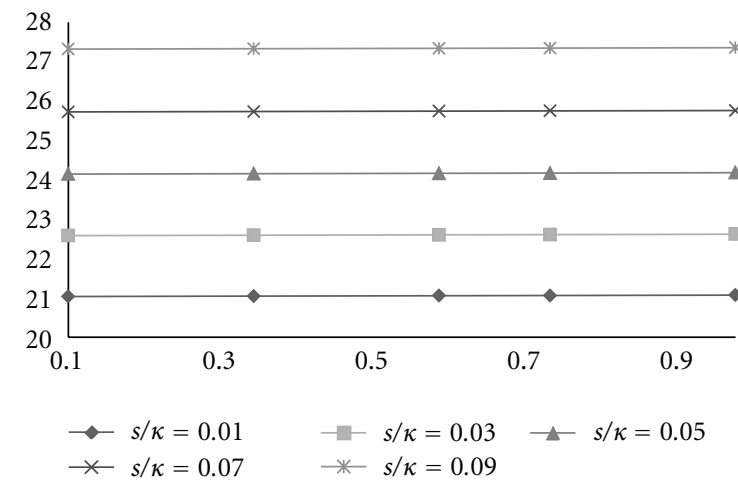

(h)

Figure 2: Continued. 


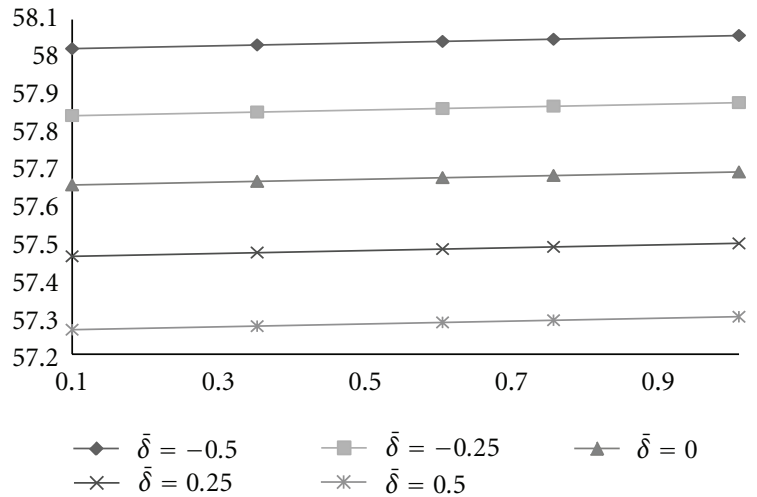

(i)

FIgURE 2: (a)-(i) The distribution of load-carrying capacity with respect to the magnetization parameter $\mu^{*}$ for various values of surface roughness $\bar{\sigma}, \bar{\varepsilon}$, aspect ratio $m$, porosity $\psi$, curvature parameters $\bar{B}, \bar{C}$, rotational inertia $s / \kappa$ and elastic deformation $\bar{\delta}$.

elastic deformation effect on the behaviour of a squeeze film between rotating porous circular plates with concentric circular pockets in the presence of a magnetic fluid lubricant. It was shown that the negative effect of roughness, porosity, and deformation can be minimized by the positive effect of magnetization choosing a suitable pocket radius in the case of negatively skewed roughness.

Efforts have been made here to deal with the combined effect of surface roughness and deformation on the squeeze film performance in curved porous-rotating annular plates in the presence of a magnetic fluid lubricant.

\section{Analysis}

Figure 1 deals with the configuration of the bearing system consisting of the annular disks.

Both the disks are considered to be elastically deformable, and their contact surfaces are assumed to be transversely rough. The upper disk moves towards the lower disk normally with an uniform velocity $\dot{h}=d h / d t$. Both the disks are assumed to have transversely rough surfaces. In view of the investigations regarding stochastic modeling of the roughness, conducted by Christensen and Tonder [1921] and Prajapati [23], the film thickness is taken as

$$
h(r, t)+\delta(r, t)+h_{s}(r, \xi)
$$

wherein $h$ denotes the smooth and unstressed part of the film thickness and $h_{s}$ is the part due to surface roughness measured from the mean level $h+\delta$, and its random character is expressed by the variable $\xi . h_{s}$ is governed by the probability density function

$$
f\left(h_{s}\right)= \begin{cases}\frac{35}{32 c}\left(1-\frac{h_{s}^{2}}{c^{2}}\right)^{3}, & -c \leq h_{s} \leq c \\ 0, & \text { otherwise }\end{cases}
$$

where $c$ is the maximum deviation from the mean film thickness. The mean $\alpha$, the standard deviation $\sigma$ and the parameter $\varepsilon$ which is the measure of symmetry of random variable $h_{s}$ are defined as

$$
\begin{gathered}
\alpha=E\left(h_{s}\right), \\
\sigma^{2}=E\left[\left(h_{s}-\alpha\right)^{2}\right], \\
\varepsilon=E\left[\left(h_{s}-\alpha\right)^{3}\right],
\end{gathered}
$$

where $E$ denotes the expected value defined by

$$
E(R)=\int_{-c}^{c} R f\left(h_{s}\right) d s .
$$

It is assumed that the upper plate lying along the surface determined by

$$
Z_{u}=h_{0} \sec \left(B r^{2}\right), \quad a<r<b
$$

approaches with normal velocity $\dot{h_{0}}=d h_{0} / d t$, to the lower plate lying along the surface

$$
Z_{u}=h_{0}\left[\sec \left(C r^{2}\right)-1\right], \quad a<r<b,
$$

where $h_{0}$ is the central distance between the plates, $B$ and $C$ are the curvature parameters of the corresponding plates. The central film thickness $h(r)$ then is defined by Bhat [11]

$$
h=h_{0}\left[1+\sec \left(B r^{2}\right)-\sec \left(C r^{2}\right)\right], \quad a<r<b .
$$

Upper and lower plates rotate with angular velocities $\Omega_{u}$ and $\Omega_{l}$, respectively, and

$$
\Omega_{r}=\Omega_{u}-\Omega_{l} .
$$

Further,

$$
\Omega^{2}=\frac{p_{a}}{\rho}\left[2 \Omega_{f}^{2}+\frac{8}{3} \Omega_{f}+2\right],
$$

where $\Omega_{f}$ is the rotation ratio $\Omega_{u} / \Omega_{l}$. Assuming axially symmetric flow of the magnetic fluid between the annular plates under an oblique magnetic field

$$
\bar{H}=(H(r) \cos \varphi(r, z), 0, H(r) \sin \varphi(r, z)),
$$


where magnitude $H$ is a function of $r$ vanishing at $r=a$ (inner radius) and $r=b$ (outer radius). Following Bhat and Deheri [10] and Bhat [11], it has been considered that

$$
H^{2}=k(r-a)(b-r),
$$

where $k=10^{14} A^{2} m^{-4}$ chosen so as to have a magnetic field of strength over $10^{5}$. The inclination $\varphi=\varphi(r, z)$ can be determined from $\nabla \times \bar{H}=0$ which assumes the form

$$
\cot \varphi \frac{\partial \varphi}{\partial r}+\frac{\partial \varphi}{\partial z}=\frac{2 r-b-a}{2(b-r)(r-a)} .
$$

The modified Reynolds equation governing the film pressure $p$ under the usual assumptions of hydromagnetic lubrication takes the form (Prajapati [23], Bhat and Deheri [12], and Patel and Deheri [34])

$$
\frac{1}{r} \frac{d}{d r}\left[r g(h) \frac{d}{d r}\left\{p-0.5 \mu_{0} \bar{\mu} H^{2}\right\}\right]=12 \mu \dot{h}+4 s G(h) .
$$

With

$$
\begin{aligned}
g(h)= & \left(h+p^{\prime} p_{a} \delta\right)^{3}+3 \alpha\left(h+p^{\prime} p_{a} \delta\right)^{2} \\
& +3\left(\alpha^{2}+\sigma^{2}\right)\left(h+p^{\prime} p_{a} \delta\right)+3 \sigma^{2} \alpha+\alpha^{3}+\varepsilon+12 \phi H_{0} \\
G(h)= & \left(h+p^{\prime} p_{a} \delta\right)^{3}+3\left(\sigma^{2}+\alpha^{2}\right)\left(h+p^{\prime} p_{a} \delta\right)+3 \alpha \sigma^{2} \\
& +\alpha^{3}+\varepsilon
\end{aligned}
$$

where $\mu_{0}$ is permeability of free space, $\bar{\mu}$ is the magnetic susceptibility of particles and $\mu$ is the viscosity of the lubricant, $\phi$ is the permeability of porous facing, $H_{0}$ is the thickness of porous medium, $\delta$ is the local elastic deformation of the porous facing, and $p_{a}$ is the reference ambient pressure. For the details regarding the deformation aspects one is requested to refer Prajapati [23, 35]. The associated boundary conditions are

$$
p(a)=0, \quad p(b)=0 .
$$

In view of the following nondimensional quantities,

$$
\begin{aligned}
& P=-\frac{h_{0}^{3} p}{\mu \dot{h}\left(b^{2}-a^{2}\right)}, \quad R=\frac{r}{a}, \quad \bar{\sigma}=\frac{\sigma}{h_{0}}, \quad \bar{\alpha}=\frac{\alpha}{h_{0}}, \\
& \bar{\varepsilon}=\frac{\varepsilon}{h_{0}^{3}}, \quad \psi=\frac{\phi H_{0}}{h_{0}^{3}}, \quad \kappa=\frac{12 \mu \dot{h}}{h_{0}^{3}}, \quad \bar{B}=B a^{2}, \\
& \bar{C}=C a^{2}, \quad \mu^{*}=-\frac{\mu_{0} \bar{\mu} k h^{3}}{\mu \dot{h}}, \quad \bar{p}=p^{\prime} p_{a}, \quad \bar{\delta}=\frac{\delta}{h}, \\
& s=\frac{3 \rho \Omega^{2}}{20 p_{a}} .
\end{aligned}
$$

$\rho$ being density of lubricant and $\Omega$ is angular velocity.
Integrating the stochastically averaged Reynolds equation (13) under the boundary conditions (15), one obtains the expression for the non-dimensional pressure distribution as

$$
\begin{aligned}
P= & \frac{0.5 \mu^{*}(1-R)(R-m)}{\left(m^{2}-1\right)} \\
& -\frac{3 D_{1}}{\left(m^{2}-1\right)}\left[\tan ^{-1}\left(E_{1} R^{2}\right)-\tan ^{-1}\left(E_{1}\right)\right] \\
& -\frac{4\left(R^{2}-1\right)}{\left(m^{2}-1\right)}\left(\frac{s}{\kappa}\right)\left(\frac{B_{2}}{A_{2}}\right) \\
& -\frac{3}{\left(m^{2}-1\right)}\left[\frac{C_{1}}{\kappa A_{1} a^{2}}\right]\left[4 \log R-\log \left[\frac{A_{1}+A_{2} R^{4}}{A_{1}+A_{2}}\right]\right],
\end{aligned}
$$

where

$$
\begin{aligned}
& A_{1}=1+3 \bar{p} \bar{\delta}++3(\bar{p} \bar{\delta})^{2}+3 \bar{\alpha}(1+\bar{p} \bar{\delta})^{2} \\
& +3\left(\bar{\alpha}^{2}+\bar{\sigma}^{2}\right)(1+\bar{p} \bar{\delta})+3 \bar{\sigma}^{2} \bar{\alpha}+\bar{\alpha}^{3}+12 \psi+\bar{\varepsilon}, \\
& A_{2}=1.5\left(\bar{B}^{2}-\bar{C}^{2}\right)\left[1+3 \bar{p} \bar{\delta}++3(\bar{p} \bar{\delta})^{2}+2 \bar{\alpha}(1+\bar{p} \bar{\delta})^{2}\right. \\
& \left.+\left(\bar{\alpha}^{2}+\bar{\sigma}^{2}\right)(1+\bar{p} \bar{\delta})\right] \\
& B_{1}=1+3 \bar{p} \bar{\delta}++3(\bar{p} \bar{\delta})^{2}+3\left(\bar{\alpha}^{2}+\bar{\sigma}^{2}\right)(1+\bar{p} \bar{\delta})+3 \bar{\sigma}^{2} \bar{\alpha} \\
& +\bar{\alpha}^{3}+\bar{\varepsilon} \\
& B_{2}=1.5\left(\bar{B}^{2}-\bar{C}^{2}\right)\left[1+3 \bar{p} \bar{\delta}++3(\bar{p} \bar{\delta})^{2}\right. \\
& \left.+\left(\bar{\alpha}^{2}+\bar{\sigma}^{2}\right)(1+\bar{p} \bar{\delta})\right] \\
& D_{1}=1+\frac{4}{3}\left(\frac{s}{\kappa}\right)\left(\frac{3 A_{2} B_{1}-A_{1} B_{2}}{A_{2}}\right) ; \quad E_{1}=\sqrt{\frac{A_{2}}{A_{1}}} ; \\
& \lambda_{1}=D_{1}\left[\tan ^{-1}\left(E_{1}\right)-\tan ^{-1}\left(E_{1} m^{2}\right)\right] ; \\
& \lambda_{2}=\frac{4\left(m^{2}-1\right)}{3}\left(\frac{s}{\kappa}\right)\left(\frac{B_{2}}{A_{2}}\right) \\
& \lambda_{3}=4 \log m-\log \left[\frac{A_{1}+A_{2} m^{4}}{A_{1}+A_{2}}\right] ; \quad \frac{C_{1}}{\kappa A_{1} a^{2}}=\frac{\lambda_{1}-\lambda_{2}}{\lambda_{3}} \text {. }
\end{aligned}
$$

The load-carrying capacity in non-dimensional form then, is calculated as

$$
W=-\frac{h_{0}^{3} w}{\mu \dot{h}\left(b^{2}-a^{2}\right)^{2}}=\frac{2 \pi}{m^{2}-1} \int_{1}^{m} R P d R
$$


which leads to

$$
\begin{aligned}
& \mathrm{W}=2 \pi\left[\frac{\mu^{*}}{24}\left(\frac{m-1}{m+1}\right)\right. \\
&-\frac{3}{\left(m^{2}-1\right)^{2}}\left\{\frac{D_{1} m^{2}}{2}+\frac{C_{1}}{\kappa A_{1} E_{1} a^{2}}\right\} \\
& \times\left\{\tan ^{-1}\left(E_{1} m^{2}\right)-\tan ^{-1}\left(E_{1}\right)\right\} \\
&+\frac{3}{\left(m^{2}-1\right)^{2}}\left\{\frac{D_{1}}{E_{1}}+\frac{C_{1} m^{2}}{2 \kappa A_{1} a^{2}}\right\} \log \left[\frac{A_{1}+A_{2} m^{4}}{A_{1}+A_{2}}\right] \\
&\left.-\frac{6 m^{2} \log m}{\left(m^{2}-1\right)^{2}}\left(\frac{C_{1}}{\kappa A_{1} a^{2}}\right)-\left(\frac{s}{\kappa}\right)\left(\frac{B_{2}}{A_{2}}\right)\right] .
\end{aligned}
$$

\section{Results and Discussion}

It is easily seen that the dimensionless film pressure is presented by (17) while (20) determines the distribution of non-dimensional load-carrying capacity It is observed from these equations that the pressure distribution and the load-carrying capacity depend on various parameters such as $\mu^{*}, \bar{\sigma}, \bar{\varepsilon}, \bar{\alpha}, m, \psi, \bar{B}, \bar{C}, s / \kappa$ and $\bar{\delta}$. These parameters respectively, describe the effect of magnetization, surface roughness, aspect ratio, porosity, curvature parameters, rotational inertia and elastic deformation.

It is noticed that for a nonporous bearing with smooth surfaces this investigation reduces to the study of Bhat and Deheri [10] dealing with a magnetic fluid-based squeeze film between annular plates in the absence of rotation and deformation. Further, considering the magnetization parameter $\mu^{*}$ to be equal to zero for a nonporous bearing with smooth surfaces, one can obtain the results of Prakash and Vij [3] when no rotation and deformation are involved. In addition, setting the magnetization parameter to be zero for a porous bearing with smooth surfaces, one can avail the results of Bhat [11] when there is no deformation. A close glance at (20) tends to indicate that the elastic deformation of the bearing decreases the load-carrying capacity. Also, it is noticed from (17) that the non-dimensional pressure increases by

$$
\frac{\mu^{*}}{2}\left[\frac{(1-R)(R-m)}{m^{2}-1}\right]
$$

while (20) establishes that the non-dimensional loadcarrying capacity gets enhanced by

$$
\frac{\mu^{*} \pi}{12}\left[\frac{m-1}{m+1}\right]
$$

as compared to the case of conventional lubricants. It is manifest that the expression for the load carrying capacity is linear with respect to the magnetization parameter and hence the dimensionless load carrying capacity increases with increasing magnetization parameter. The magnetization results in an improved performance because it increases the viscosity of the lubricant leading to an increase in pressure, thus giving increased load-carrying capacity. It is revealed that the aspect ratio plays a crucial role in improving the performance of a magnetic fluid-based rough bearing system. Besides, the expression for non-dimensional pressure distribution indicates that elastic deformation of the bearing significantly distorts the profile of the pressure distribution.

It is seen that the transverse surface roughness adversely affects the performance of the bearing system and this negative effect turns out to be more significant owing to elastic deformation. Probably, this may be due to the fact that the surface roughness of the bearing system retards the motion of lubricant, resulting in decreased load-carrying capacity.

The distribution of load-carrying capacity with respect to the magnetization parameter for various values of $\bar{\sigma}, \bar{\varepsilon}$, $\bar{\alpha}, m, \psi, \bar{B}, \bar{C}, s / \kappa$ and $\bar{\delta}$ given in Figures $2(\mathrm{a})-2(\mathrm{i})$, suggests that the load-carrying capacity marginally increases due to the magnetic fluid lubricant. A close scrutiny of the figures makes it clear that the performance of bearing systems gets nominally improved which becomes more sharp in the cases of $\bar{\sigma}, \bar{\alpha}, \psi$ and $\bar{\delta}$ when negatively skewed roughness is involved.

It is easily noticed that the curvature parameters negligibly increase the load-carrying capacity unlike, the case of circular plates as investigated by Shimpi and Deheri [33]. Furthermore, it is seen that increase in the loadcarrying capacity is comparatively less here contrasting the case of circular geometry discussed by Shimpi and Deheri [33].

The profile of the distribution of non-dimensional loadcarrying capacity with respect to the standard deviation is presented in Figures 3(a)-3(f). Here, it is noted that the standard deviation has an adverse effect on the performance of the bearing system in the sense that the load-carrying capacity decreases considerably due to the standard deviation. However, this decrease is relatively less in the case of the aspect ratio, while this rate of decrease is more in the case of porosity. It is also found that the porosity decreases the already decreased load-carrying capacity due to the standard deviation. It is revealed that for the large value of deformations this negative effect is more pronounced.

One can see the variation of non-dimensional loadcarrying capacity with respect to $\bar{\alpha}$ (positive) from Figures $4(\mathrm{a})-4(\mathrm{f}), \bar{\alpha}$ (positive) degreases the load-carrying capacity. It is seen that $\bar{\alpha}$ (negative) induces an increase in the loadcarrying capacity. But the effect of deformation on the variation of the load-carrying capacity with respect to $\bar{\alpha}$ is not that sharp as its effect is nominal. It is interesting to note that the effect of the porosity on the distribution of the loadcarrying capacity with respect to the variance is negligible.

The profile for the distribution of the load-carrying capacity with respect to skewness is depicted in Figures 5(a)5(d). It is found that the skewness follows the trends of the variance. However, one can easily see that the positive effect of negatively skewed roughness is relatively sharp as compared to the effect of negative variance. Furthermore, one can visualize that the combined effect of negatively skewed roughness and negative variance is significantly positive in most of the situations. 


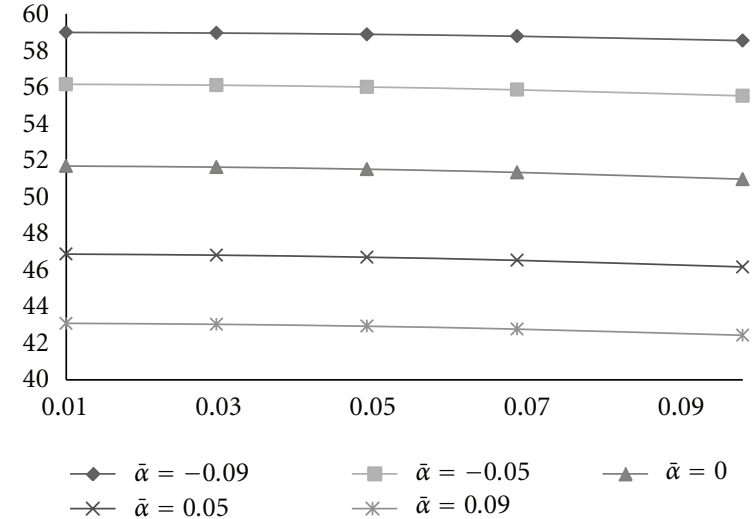

(a)

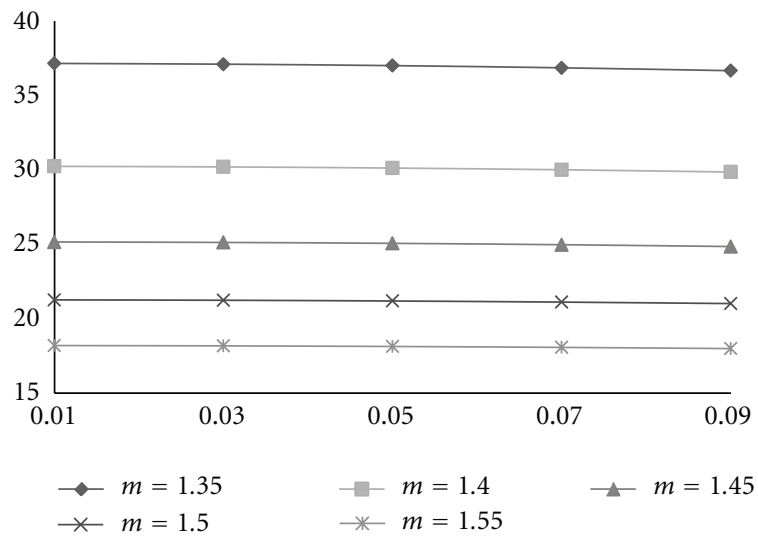

(c)

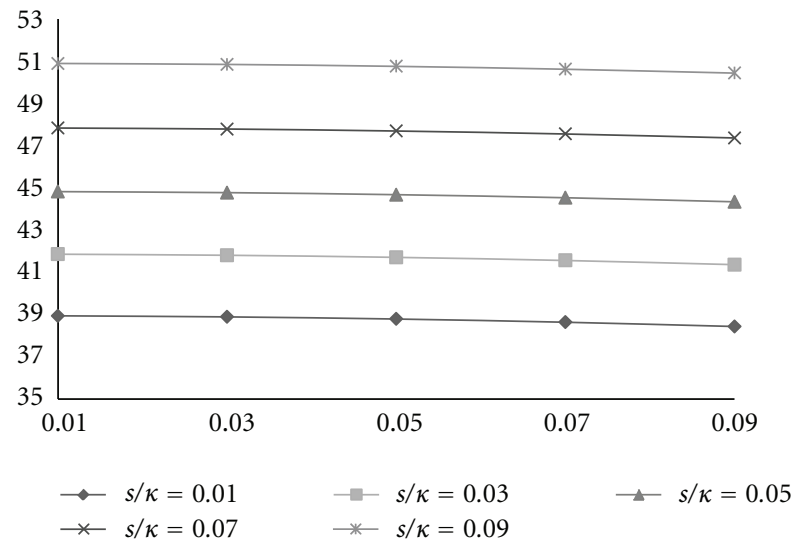

(e)

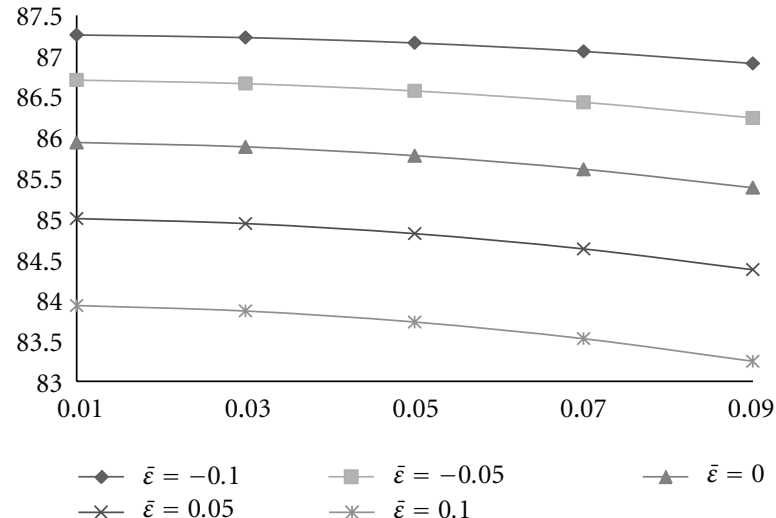

(b)

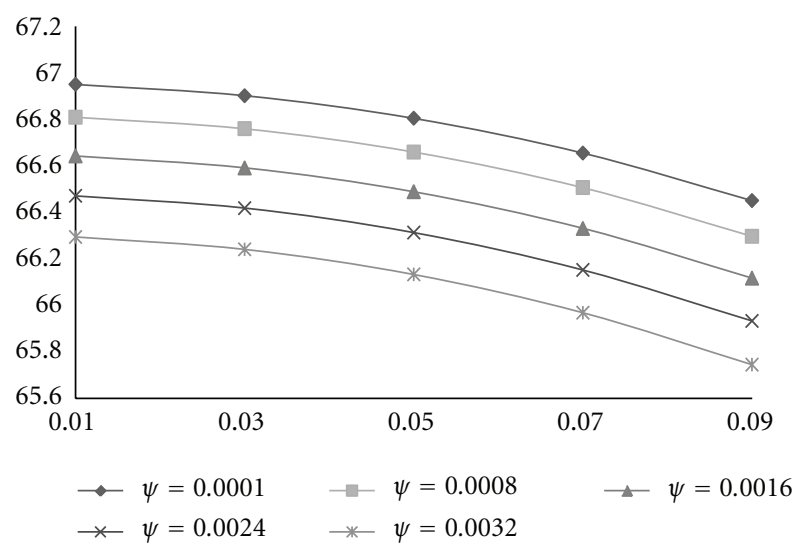

(d)

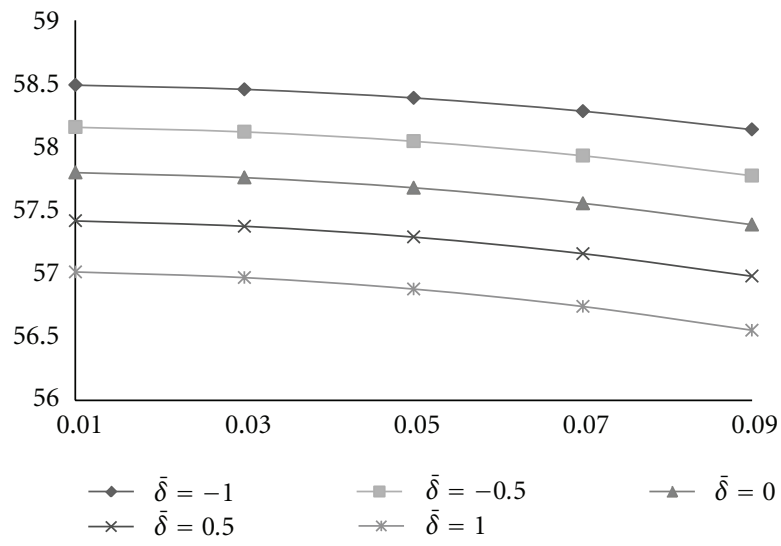

(f)

FiguRe 3: (a)-(f) The distribution of load-carrying capacity with respect to $\bar{\sigma}$ for various values of $\bar{\alpha}, \bar{\varepsilon}, m, \psi, s / \kappa$ and $\bar{\delta}$.

TABLE 1

\begin{tabular}{lcccc}
\hline Quantity & & Load-carrying capacity in this paper (I) \\
Without consideration & Without consideration \\
\hline $\bar{\varepsilon}=-0.05$ & $\mu^{*}$ & 0.570791 & 0.570783 & 0.579428 \\
& $\bar{\alpha}$ & 0.25419 & 0.25414 & 0.44230 \\
& $\bar{\sigma}$ & 0.51264 & 0.50614 & 0.70504 \\
& $\bar{\delta}$ & 0.526243 & 0.524512 & 0.870162 \\
& $\psi$ & 0.502678 & 0.599395 & 0.8573432 \\
\hline
\end{tabular}



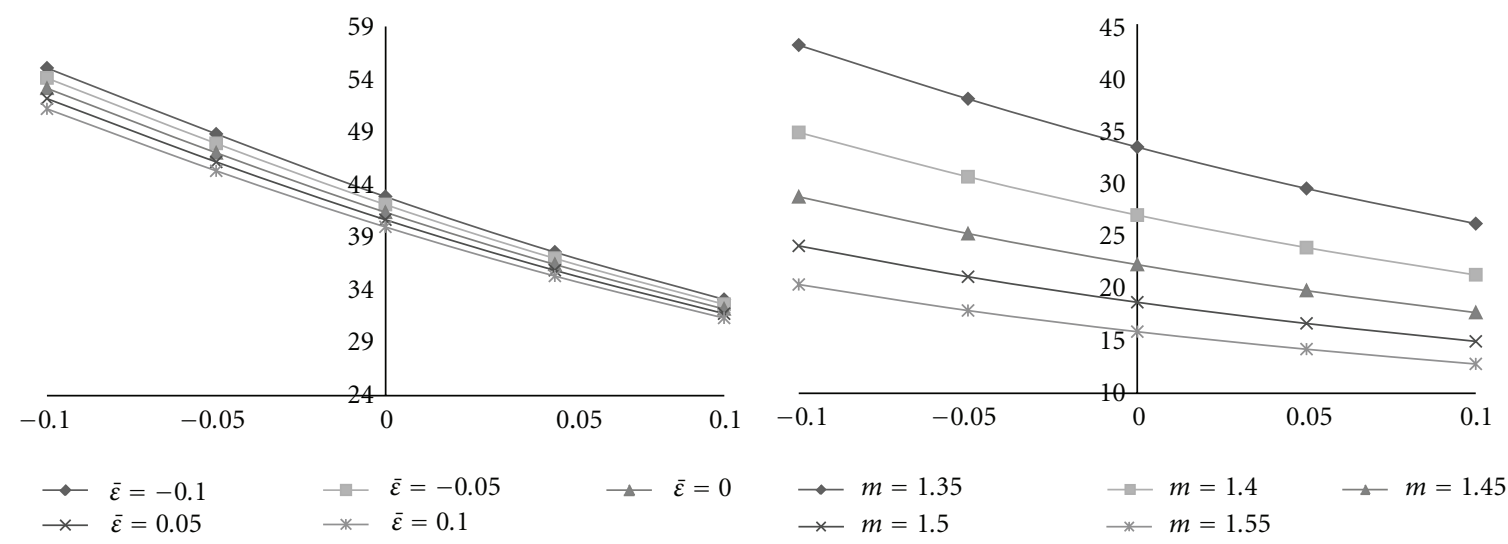

(a)
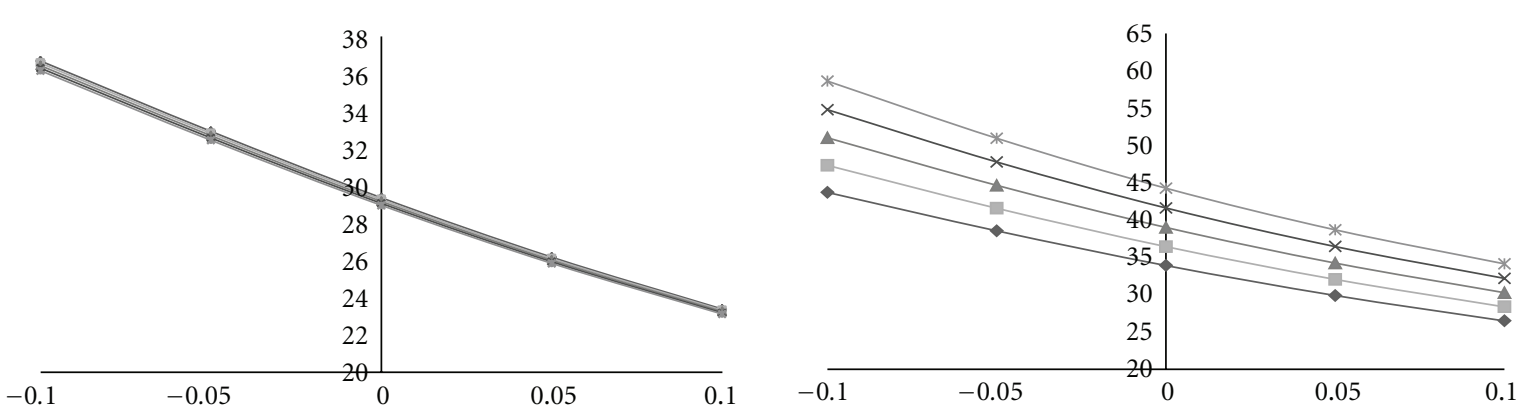

$$
\begin{aligned}
& \rightarrow \psi=0.0001 \quad \rightarrow \psi=0.0008 \quad \rightarrow \psi=0.0016 \\
& \rightarrow \psi=0.0024 \quad \longrightarrow \psi=0.0032
\end{aligned}
$$

$$
\rightarrow s / \kappa=0.01
$$$$
-s / \kappa=0.03
$$$$
\text { * } s / \kappa=0.09
$$$$
\multimap s / \kappa=0.05
$$

(c)

(d)

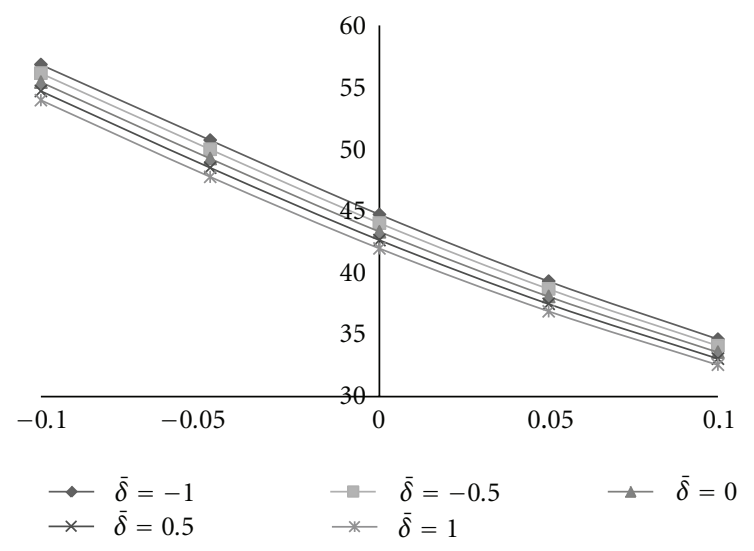

(e)

FIgURE 4: (a)-(e) Variation of load-carrying capacity with respect to $\bar{\alpha}$ and $\bar{\varepsilon}, m, \psi, s / \kappa, \bar{\delta}$.

TABle 2

\begin{tabular}{lcccc}
\hline Quantity & & & Load carrying capacity in this manuscript I \\
Without consideration & Without consideration \\
\hline $\bar{\alpha}=-0.03$ & & With consideration & 0.3704783 & 0.254218 \\
& $\mu^{*}$ & 0.3707221 & 0.25414 & - \\
& $\bar{\delta}$ & 0.25419 & 0.101214 & 0.130504 \\
& $\bar{\sigma}$ & 0.126423 & 0.152452 & 0.870162 \\
& $\bar{\varepsilon}$ & 0.15263 & 0.13395 & 0.14432 \\
\hline
\end{tabular}




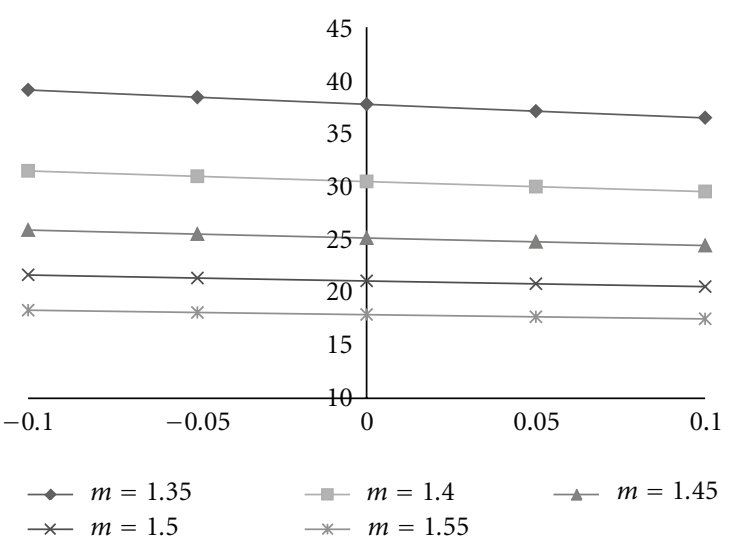

(a)

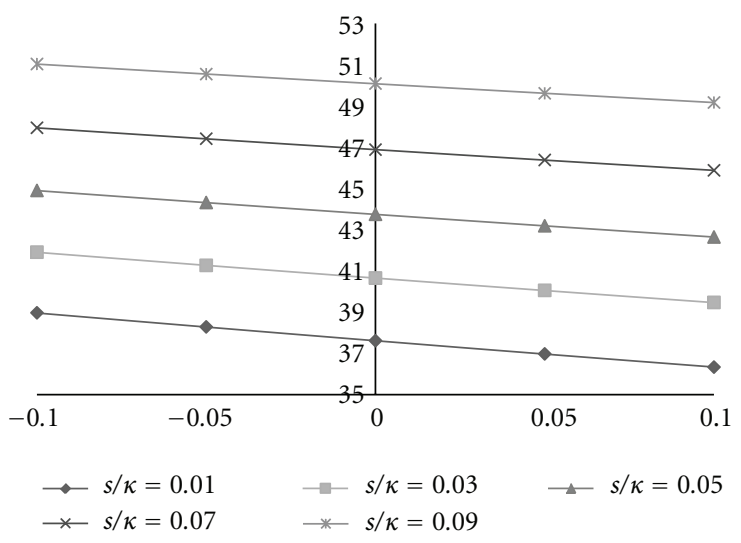

(c)

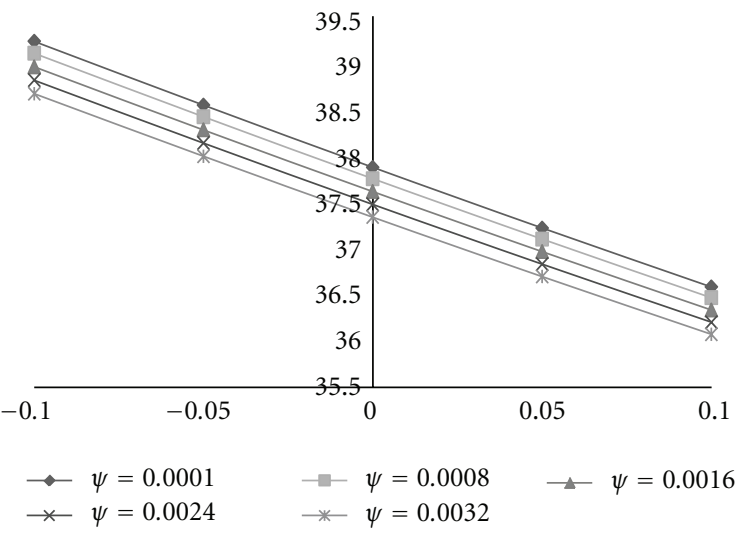

(b)

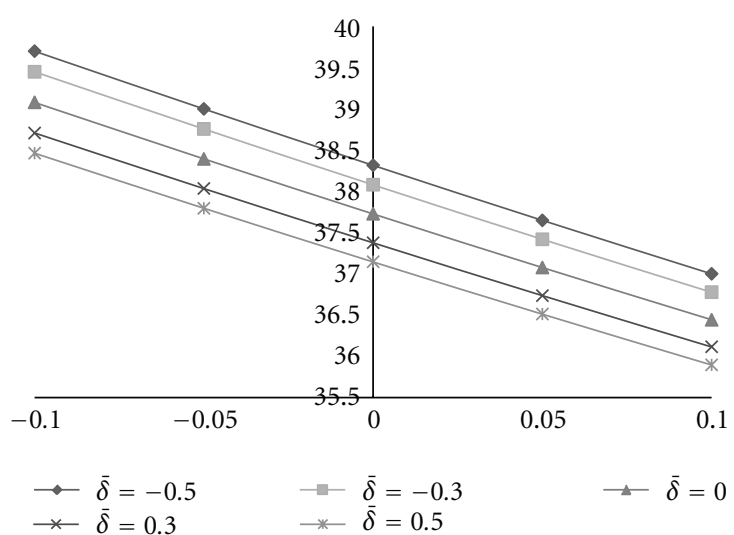

(d)

FIGURE 5: (a)-(d) Variation of load-carrying capacity with respect to $\bar{\varepsilon}$ and $m, \psi, s / \kappa, \bar{\delta}$.

TABle 3

\begin{tabular}{lcccc}
\hline Quantity & & & Load-carrying capacity in this paper I \\
Without consideration & Without consideration \\
\hline$\psi=0.0015$ & & With consideration & 0.320473 & 0.98518 \\
& $\mu^{*}$ & 0.320621 & 0.26226 & 0.99429 \\
& $\bar{\alpha}$ & 0.26237 & 0.99323 & 1.2645 \\
& $\bar{\sigma}$ & 0.98723 & 0.85456 & - \\
& $\bar{\delta}$ & 0.85243 & 0.92258 & 1.69842 \\
\hline $\bar{\varepsilon}$ & 0.93345 & & \\
\hline
\end{tabular}

The effect of the aspect ratio on the distribution of loadcarrying capacity is presented in Figures 6(a)-6(c). It is observed that the load-carrying capacity decreases sharply with the increase in the aspect ratio and hence it has significant effect on the performance of bearing system. However, the effect of porosity on the distribution of loadcarrying capacity with respect to the aspect ratio is almost negligible as can be seen from Figure 6(a).

Figures 7(a)-7(b) make it clear that the effect of porosity on the performance of the bearing system is considerably adverse in the sense that the load-carrying capacity decreases sharply due to porosity and this effect is more pronounced in the case of rotational inertia. Besides, there is a strong negative effect due to porosity when large values of deformation are involved.

Figure 8(a) suggests that the rotational inertia increases the load-carrying capacity and this effect is more pronounced when smaller values of deformations are involved. This Figure also, underlines that unlike the case of circular geometry the deformation induces sharp decrease in the load-carrying capacity. Lastly, Figure 8(b) dealing with the variation of load-carrying capacity with respect to the curvature parameters indicates that the upper plate's curvature parameter decreases the load-carrying capacity while the 

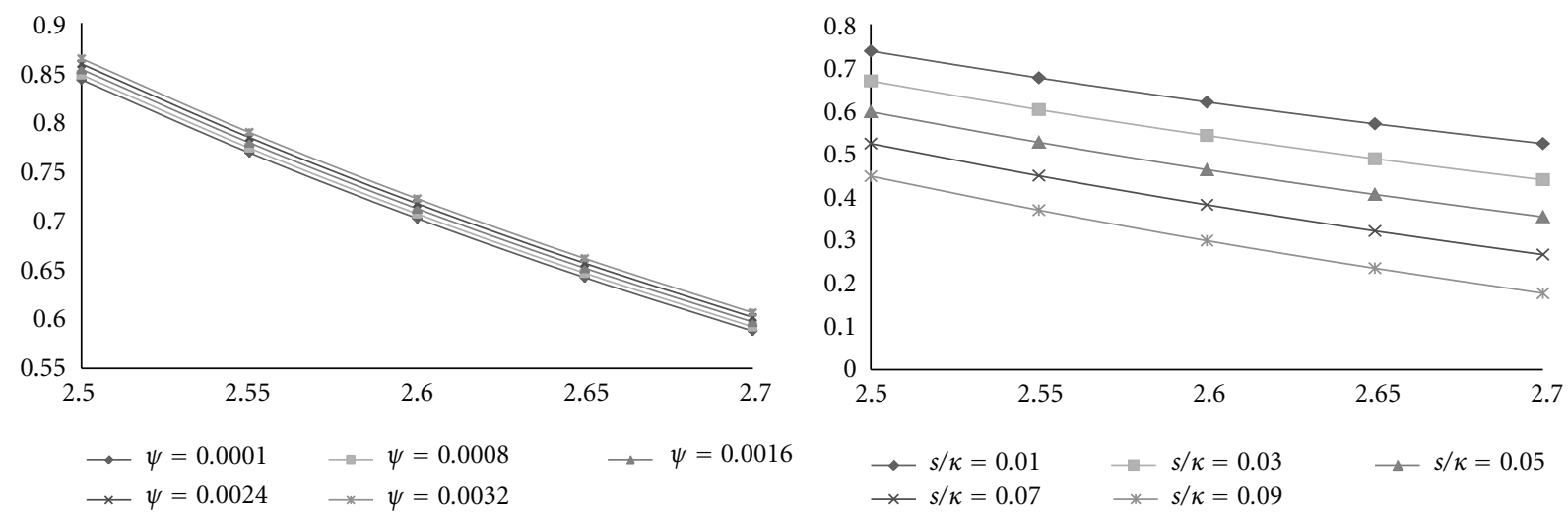

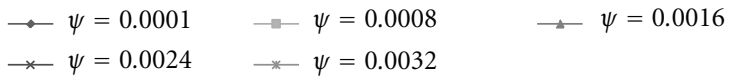

(a) (b)

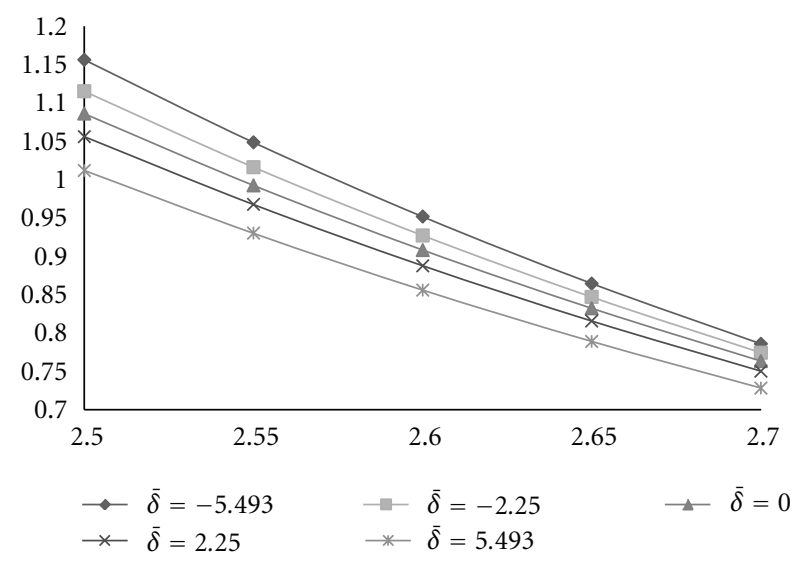

(c)

FIGURE 6: (a)-(c) Variation of load-carrying capacity with respect to $m$ and $\psi, s / \kappa, \bar{\delta}$.

TABLE 4

\begin{tabular}{lcccc}
\hline Quantity & & With consideration & $\begin{array}{c}\text { Load-carrying capacity in this paper II } \\
\text { Without consideration }\end{array}$ & Without consideration \\
\hline $\bar{\delta}=-5.493$ & $\mu^{*}$ & 0.270526 & 0.350378 & 1.52542 \\
& $\bar{\alpha}$ & 0.425346 & 0.365367 & 1.53761 \\
& $\bar{\sigma}$ & 0.123345 & 0.401358 & 1.64243 \\
& $\bar{\varepsilon}$ & 0.142563 & 0.35213 & - \\
& & 0.15734 & 0.42134 & 1.63452 \\
\hline
\end{tabular}

opposite is the trend of lower plate's curvature parameter. In addition, the effect of upper plate curvature parameter is more pronounced when smaller values of the lower plate's curvature parameter are involved.

In the absence of rotation a comparison of the present case with the corresponding case of Bhat and Deheri [10] reveals that the load-carrying capacity is more increased here resulting in an overall improved performance at least in the case of negatively skewed roughness choosing suitably the curvature parameters. An examination of some of the figures presented here reveals that the combined negative effect of porosity and standard deviation is more prominent when large values of deformation are involved. Of course, the rotational inertia adds to this negative effect. It is suggested that the adverse effect of porosity, standard deviation, rotational inertia and deformation can be compensated up to certain extent by the positive effect of the magnetic fluid lubricant in the case of negatively skewed roughness by picking up suitable values of the aspect ratio particularly, when negative variance occurs.

\section{Validation}

A close scrutiny of the results available in this paper indicates that the effect of small values of the curvature parameters is 


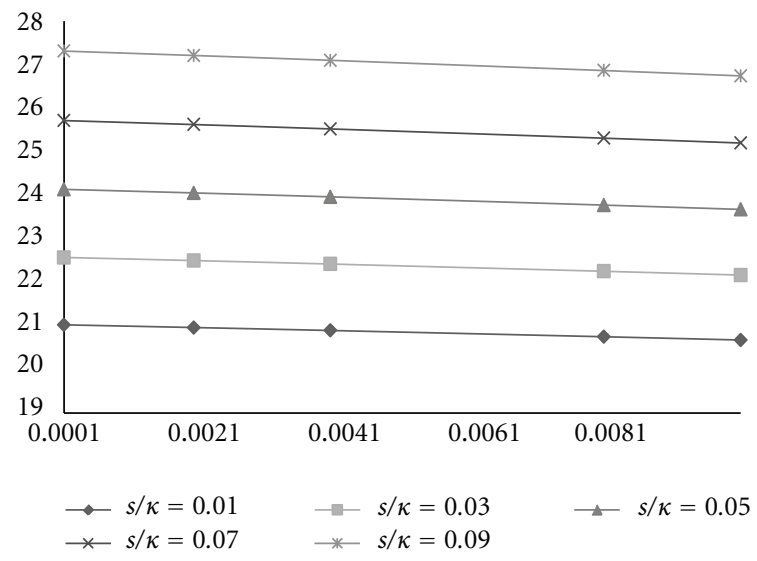

(a)

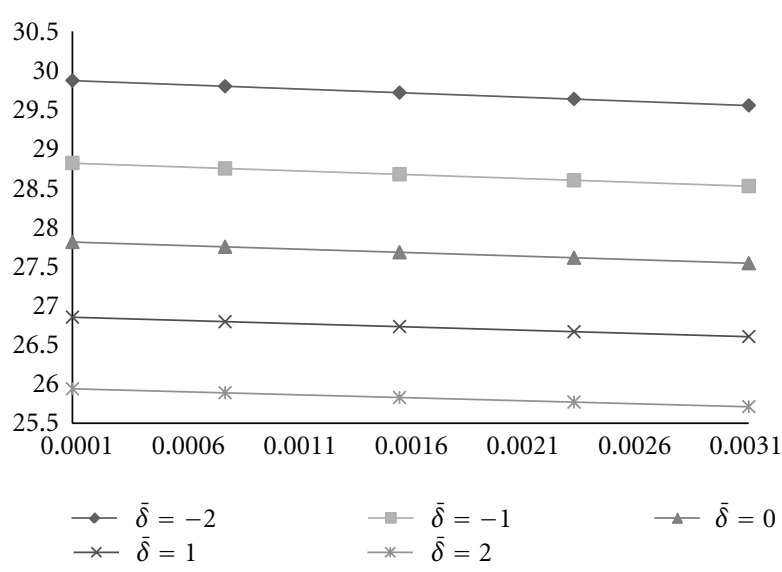

(b)

FIGURE 7: (a)-(b) Variation of load-carrying capacity with respect to $\psi$ and $s / \kappa, \bar{\delta}$.

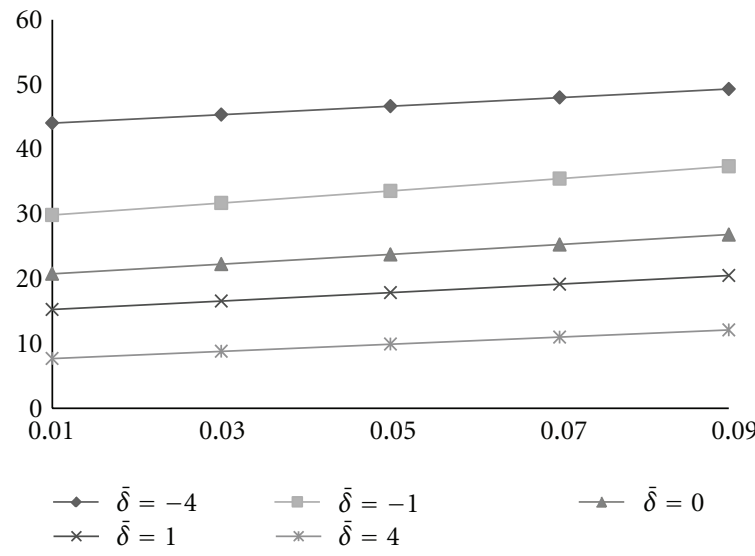

(a)

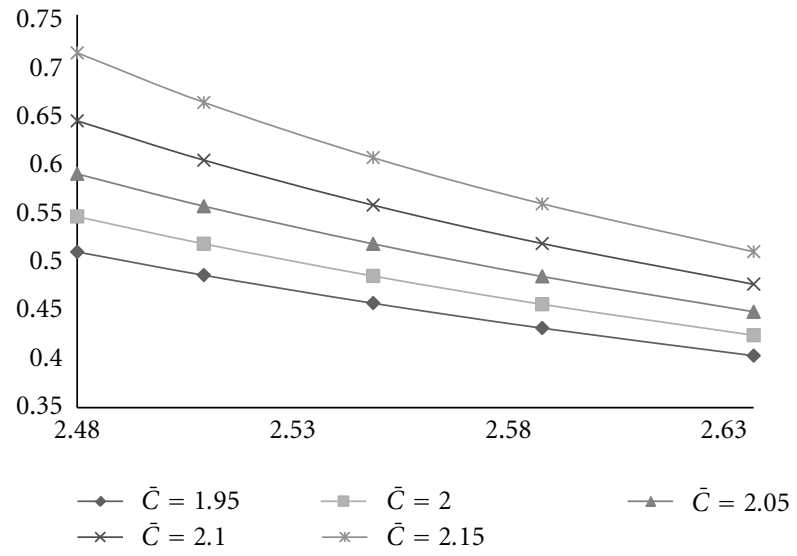

(b)

FIgURE 8: (a) Variation of load-carrying capacity with respect to $s / \kappa$ and $\bar{\delta}$ (b) Variation of load-carrying capacity with respect to $\bar{B}$ and $\bar{C}$.

more sharp as compared to that of Lin et al. [16] in spite of the fact that the roughness and deformation bring down the load-carrying capacity.

In order to enhance the validation of the conclusions of this paper the following sets of comparison have been made with other well known published works.

In Tables 1, 2 and 3 (I) represents the load-carrying capacity without considering the given quantity from Patel and Deheri [34]

In Table 4 (II) represents the load-carrying capacity without considering the given quantity from Shimpi and Deheri [33].

\section{Conclusion}

It is clearly seen that most of the parameters appear to have adverse effect on the performance of the bearing system and hence, from the bearing's life period point of view, this investigation makes it clear that the roughness must be accounted for while designing the bearing system even if suitable values of magnetization parameter, rotational inertia, and curvature parameters are considered as the effect of the deformation is equally significant here. It is appealing to note that the bearing can support a load even in the absence of flow in spite of the fact that there are several factors abound affecting the system adversely (porosity, standard deviation, and deformation affecting the most) which never happens in the case of conventional lubricants. Lastly, it is noted that even the aspect ratio may play an important role in improving the performance of this type of bearing system considering the moderate values of deformation and rotational inertia.

\section{Acknowledgments}

The authors gratefully acknowledge the fruitful comment, remarks, and suggestions of the reviewers which led to an overall improvement in the presentation of the paper. Further, the authors appreciate the valuable suggestions of the reviewers for the inclusion of a section entitled validation. 


\section{References}

[1] F. R. Archibald, "Load capacity and time relations for squeeze films," Journal of Lubrication Technology, vol. 78, pp. A231A245, 1956.

[2] H. Wu, "An analysis of the squeeze film behavior for porous annular disks," Journal of Lubricant Technology, vol. 92, pp. 593-596, 1972.

[3] J. Prakash and S. K. Vij, "Load capacity and time-height relations for squeeze films between porous plates," Wear, vol. 24, no. 3, pp. 309-322, 1973.

[4] P. R. K. Murti, "Squeeze films in curved circular plates," Journal of Lubrication Technology, vol. 97, no. 4, pp. 650-652, 1975.

[5] D. F. Hays, "Squeeze films for rectangular plates," Journal of Basic Engineering, vol. 58, pp. 243-251, 1963.

[6] J. L. Gupta and K. H. Vora, "Analysis of squeeze films between curved annular plates," Journal of Lubrication Technology, vol. 102, no. 1, pp. 48-50, 1980.

[7] R. M. Patel and G. M. Deheri, "Magnetic fluid based squeeze film between two curved plates lying along the surfaces determined by secant functions," Indian Journal of Engineering and Materials Sciences, vol. 9, no. 1, pp. 45-48, 2002.

[8] V. K. Agrawal, "Magnetic-fluid-based porous inclined slider bearing," Wear, vol. 107, no. 2, pp. 133-139, 1986.

[9] P. D. S. Verma, "Magnetic fluid-based squeeze film," International Journal of Engineering Science, vol. 24, no. 3, pp. 305401, 1986.

[10] M. V. Bhat and G. M. Deheri, "Squeeze film behaviour in porous annular discs lubricated with magnetic fluid," Wear, vol. 151, no. 1, pp. 123-128, 1991.

[11] M. V. Bhat, Lubrication with a Magnetic Fluid, Team Spirit, India Pvt, 2003.

[12] M. V. Bhat and G. M. Deheri, "Magnetic-fluid-based squeeze film in curved porous circular discs," Journal of Magnetism and Magnetic Materials, vol. 127, no. 1-2, pp. 159-162, 1993.

[13] M. B. Ajwaliya, On certain theoretical aspects of lubrication [Ph.D. thesis], Sardar Patel University, Vallabh Vidyanagar, Gujarat, India, 1984.

[14] T. A. Osman, G. S. Nada, and Z. S. Safar, "Static and dynamic characteristics of magnetized journal bearings lubricated with ferrofluid," Tribology International, vol. 34, no. 6, pp. 369-380, 2001.

[15] S. R. Tripathi, M. V. Bhat, and R. C. Shah, "Magnetic fluid based squeeze film between porous annular curved plates with the effect of rotational inertia," Pramana, vol. 58, no. 3, pp. 545-550, 2002.

[16] J. R. Lin, R. F. Lu, and W. H. Liao, "Analysis of magnetohydrodynamic squeeze film characteristics between curved annular plates," Industrial Lubrication and Tribology, vol. 56, no. 5, pp. 300-305, 2004.

[17] H. B. Liu, J. S. Li, Y. J. Xue, and W. Ma, "Study on the friction characteristics of different lubrication modes under alternating magnetic field," Key Engineering Materials, vol. 455, pp. 490-494, 2011.

[18] S. T. Tzeng and E. Saibel, "Surface roughness effect on slider bearing lubrication," ASLE Transactions, vol. 10, no. 3, pp. 334-338, 1967.

[19] H. Christensen and K. C. Tonder, "Tribology of rough surfaces: stochastic models of hydrodynamic lubrication," SINTEF Report 10/69-18, 1969.

[20] H. Christensen and K. C. Tonder, "Tribology of rough surfaces: parametric study and comparison of lubrication model," SINTEF Report 22/69-18, 1969.
[21] H. Christensen and K. C. Tonder, "The hydrodynamic lubrication of rough bearing surfaces of finite width," in Proceedings of ASME-ASLE Lubrication Conference, pp. 12-15, Cincinnati, Ohio, USA, October 1970, Paper no.70-lub-7.

[22] J. Prakash and K. Tiwari, "Roughness effects in porous circular squeeze-plates with arbitrary wall thickness," Journal of Lubrication Technology, vol. 105, no. 1, pp. 90-95, 1983.

[23] B. L. Prajapati, "Behaviour of squeeze film between rotating porous circular plates: surface roughness and elastic deformation effects," Pure and Applied Mathematical Science, vol. 33, no. 1-2, pp. 27-36, 1991.

[24] S. K. Guha, "Analysis of dynamic characteristics of hydrodynamic journal bearings with isotropic roughness effects," Wear, vol. 167, no. 2, pp. 173-179, 1993.

[25] J. L. Gupta and G. M. Deheri, "Effect of roughness on the behavior of squeeze film in a spherical bearing," Tribology Transactions, vol. 39, no. 1, pp. 99-102, 1996.

[26] P. I. Andharia, J. L. Gupta, and G. M. Deheri, "Effects of transverse roughness on the behavior of squeeze film in spherical bearings," International Journal of Applied Mechanics and Engineering, vol. 4, no. 1, pp. 19-24, 1999.

[27] P. I. Andharia, J. L. Gupta, and G. M. Deheri, "Effect of surface roughness on hydrodynamic lubrication of slider bearings," Tribology Transactions, vol. 44, no. 2, pp. 291-297, 2001.

[28] C. H. Hsu, R. F. Lu, J. R. Lin, and C. Lai, "Combined effects of surface roughness and rotating inertia on the squeeze film characteristics of parallel circular disks," Journal of Marine Science and Technology, vol. 17, no. 1, pp. 60-66, 2009.

[29] M. E. Shimpi and G. M. Deheri, "Magnetic fluid based rough short bearing," Journal of the Balkan Tribological Association, vol. 16, no. 4, pp. 484-497, 2010.

[30] L. L. Ting, "Engagement behavior of lubricated porous annular disks," Wear, vol. 34, pp. 159-182, 1975.

[31] J. Prakash and H. Peeken, "The combined effect of surface roughness and elastic deformation in the hydrodynamic slider bearing problem," ASLE Transactions, vol. 28, no. 1, pp. 69-74, 1985.

[32] A. Chatchai and M. Mongkol, "Influence of surface roughness on elastohydrodynamic journal bearings with non-newtonian lubricants," in Advanced Tribology, part 3, pp. 50-51, 2010.

[33] M. E. Shimpi and G. M. Deheri, "Surface roughness and elastic deformation effects on the behaviour of the magnetic fluid based squeeze film between rotating porous circular plates with concentric circular pockets," Tribology in Industry, vol. 32, no. 2, pp. 21-30, 2010.

[34] R. M. Patel and G. M. Deheri, "An analysis of magnetic fluid based squeeze film between curved plates," Journal of National Academy of Mathematics, vol. 16, no. 1, pp. 74-84, 2002.

[35] B. L. Prajapati, "Squeeze film behaviour between rotating porous circular plates with a concentric circular pocket: surface roughness and elastic deformation effects," Wear, vol. 152, no. 2, pp. 301-307, 1992. 

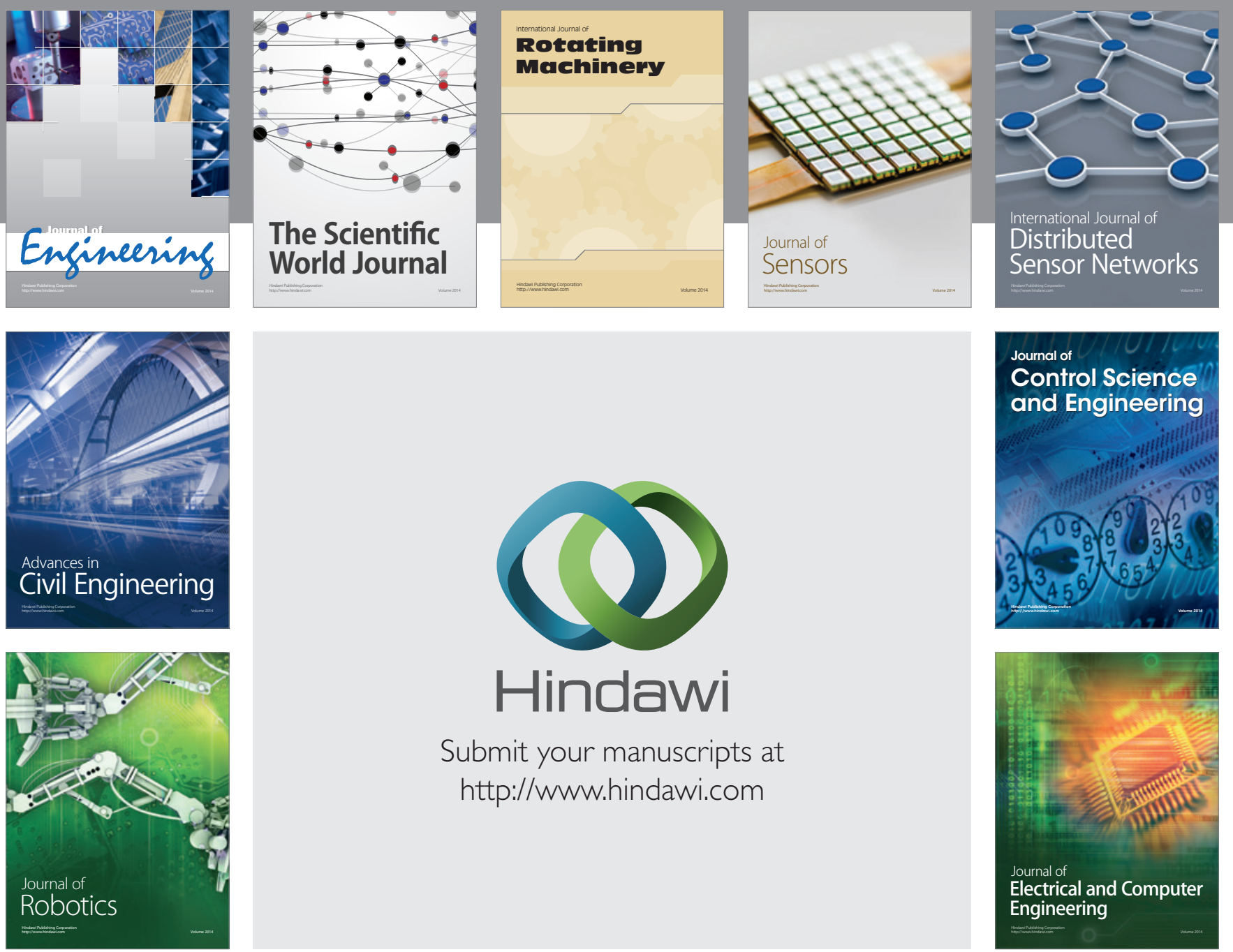

Submit your manuscripts at

http://www.hindawi.com
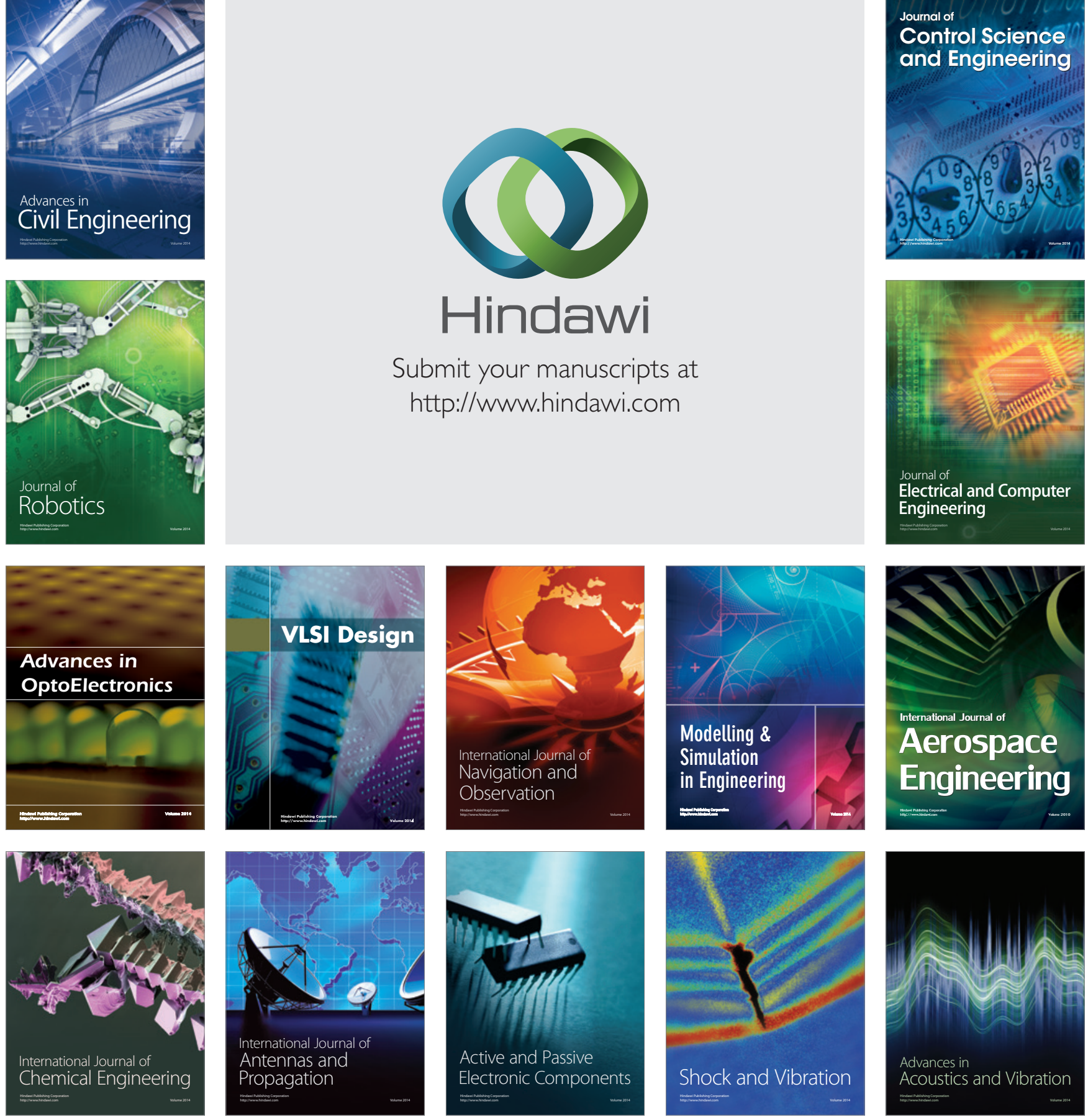